\title{
NHẬN THỨC VỀ HIV/AIDS VÀ THÁI Độ KỲ THỊ CỦA NGƯờI DẦN CộNG ĐỒNG ĐỐI VỚI TRẺ EM BI ẢNH HƯởNG BỞI HIV/AIDS: NGHIÊN CỨU TẠI QUẬN 8 VÀ QUẬN BÌNH THẠNH, THÀNH PHỐ HỔ CHÍ MINH
}

\author{
Võ Hoàng Sơn ${ }^{{ }^{*}}$ \\ ${ }^{a} H o ̣ c$ viện Khoa học Xã hội, Viện Hàn lâm Khoa học Xã hội Việt Nam, Hà Nội, Việt Nam \\ "Tác giả liên hệ: Email: sonvh2010@ gmail.com \\ Lịch sử bài báo \\ Nhận ngày 15 tháng 11 năm 2017 \\ Chỉnh sửa ngày 12 tháng 12 năm 2017 | Chấp nhận đăng ngày 18 tháng 12 năm 2017
}

\section{Tóm tắt}

Sử dụng dũ liệu định lương tù đề tài nghiên cúu của chính tác giả "Kỳ thị đối với trẻ bi ảnh huơong bởi HIV/AIDS: Nghiên cúu tại Quân 8 và Quận Bình Thạn, Thành phố Hồ Chí Minh", qua khảo sát 200 nguoòi dân cộng đồng tại hai Quận, bài viết phân tích nhận thức về HIV/AIDS và thái độ kỳ thị của người dân cộng đồng đối với trẻ em bị ảnh huởng bởi HIV/AIDS. Kết quả phân tích cho thấy nhận thức đúng toàn diện về HIV/AIDS của nguời dân chua cao, vẫn còn nhầm lẫn nhiều về HIV/AIDS. Thái độ kỳ thị của nguoời dân trong cộng đồng đối với trẻ em bị ảnh huơong bởi HIV vẫn còn rất cao, đặc biệt, đối với các tình huống liên quan trục tiếp đến con, cháu họ thì sự kỳ thị lại càng thể hiện rõ hơn. Định kiến gán nhãn của người dân cộng đồng đối với người có HIV còn khá nặng nề. Thế nhung, định kiến và nhầm lẫn về HIV không tác động đến thái độ kỳ thị của nguoời dân. Kiểm định cho thấy, giới tính, trình độ học vấn, nghề nghiệp và chưa hiểu biết đầy đủ về HIV là nhũng nhân tố ảnh hương đến sụ ngăn cản không cho trẻ em bị ảnh huởng bởi HIV học chung với trẻ khác.

Từ khóa: Nhận thức về HIV/AIDS; Thái độ kỳ thị; Trẻ em bị ảnh hưởng bởi HIV/AIDS.

Mã số định danh bài báo: http://tckh.dlu.edu.vn/index.php/tckhdhdl/article/view/362

Loại bài báo: Bài báo nghiên cứu gốc có bình duyệt

Bản quyền @ 2018 (Các) Tác giả.

Cấp phép: Bài báo này được cấp phép theo CC BY-NC-ND 4.0 


\title{
KNOWLEDGE ON HIV/AIDS AND STIGMA OF THE COMMUNITY TOWARD CHILDREN AFFECTED BY HIV/AIDS: RESEARCH CONDUCTED IN DISTRICT 8 AND BINHTHANH DISTRICT, HOCHIMINH CITY
}

\author{
Vo Hoang Son ${ }^{\text {** }}$ \\ ${ }^{a}$ The Graduate Academy of Social Sciences, The Vietnam Academy of Social Sciences, Hanoi, Vietnam \\ *Corresponding author: Email: sonvh2010@gmail.com
}

\author{
Article history \\ Received: November $15^{\text {th }}, 2017 \mid$ Received in revised form: December $12^{\text {th }}, 2017$ \\ Accepted: December $18^{\text {th }}, 2017$
}

\begin{abstract}
Using quantitative data from a research by the author titled "Stigma toward children affected by HIV/AIDS: A research conducted in District 8 and Binhthanh District, Hochiminh City", involving 200 people in the two Districts, the article analyses HIV/AIDS knowledge and stigma of the community toward children affected by HIVIAIDS. The results show that the accuracy of the people's knowledge on HIV/AIDS is not high. There are still many misperceptions. People's attitude towards children affected by HIV/AIDS is highly stigmatized, especially in situations where HIV/AIDS patients are their own children and grandchildren, the stigma is more apparent. The labelling of the community towards people living with HIV is quite heavy. However, prejudice and misperceptions about HIV do not affect people's attitude. The results of the analysis show that gender, education, occupation, and lack of complete knowledge about HIV are factors that prevent the children affected by HIV from going to school together with other children.
\end{abstract}

Keywords: Children affected by HIV/AIDS; Discrimination; Knowledge on HIV/AIDS.

Article identifier: http://tckh.dlu.edu.vn/index.php/tckhdhdl/article/view/362

Article type: (peer-reviewed) Full-length research article

Copyright (C) 2018 The author(s).

Licensing: This article is licensed under a CC BY-NC-ND 4.0 


\section{GIỚI THIỆU}

Kỳ thị liên quan đến HIV/AIDS là một vấn đề toàn cầu, mà cả thế giới nói chung và Việt Nam nói riêng đang cùng nhau giải quyết để đạt được mục tiêu "Không còn kỳ thị với người có HIV" do chương trình phối hợp của Liên hợp quốc về HIV/AIDS (UNAIDS) hướng đến nhằm kết thúc dịch HIV/AIDS vào năm 2030 (UNAIDS, 2010). Nhìn lại trong 30 năm đương đầu với HIV/AIDS, thì kỳ thị liên quan đến HIV được coi là trở ngại chính đối với sự thành công và loại trừ được dịch AIDS. Báo cáo phân tích tình hình trẻ em năm 2010 của Quỹ Nhi đồng Liên hợp quốc (UNICEF) đã ghi nhận những thành công nhanh chóng của Việt Nam về kinh tế và tiến bộ đáng kể về xã hội, khi chỉ trong hai thập kỷ qua đã đạt được vị thế quốc gia có thu nhập trung bình thấp vào năm 2009. Tuy nhiên, báo cáo cũng nhấn mạnh rằng mục tiêu liên quan đến HIV/AIDS, trong đó vấn đề kỳ thị phân biệt đối xử với người có HIV vẫn chưa hoàn toàn đạt được. Đó là một trong những rào cản chính đến hiệu quả của chương trình dự phòng và chăm sóc điều trị HIV/AIDS (Rebeca, Vũ, \& Nguyễn, 2011). Chính vì vậy, nâng cao nhận thức của người dân về HIV/AIDS để đảm bảo mọi người có hiểu biết đúng, tránh lây nhiễm HIV và góp phần giảm kỳ thị là một mục tiêu quan trọng và xuyên suốt trong chương trình phòng, chống HIV/AIDS tại Việt Nam. Ngay trong Chiến lược quốc gia phòng, chống HIV/AIDS đến năm 2020 và tầm nhìn đến 2030 , mục tiêu cụ thể đầu tiên đã xác định tăng tỷ lệ người dân trong độ tuổi tù 15 đến 49 tuổi có hiểu biết đầy đủ về HIV/AIDS đạt 80\% vào năm 2020 (Uỷ ban Quốc gia Phòng chống HIV/AIDS, ma túy, mại dâm, 2012). Kết quả điều tra đánh giá các mục tiêu trẻ em và phụ nữ - MICS năm 2014, đã phản ảnh rằng, có $94.5 \%$ phụ nữ trong độ tuổi từ $15-49$ đã nghe về HIV/AIDS và $79.7 \%$ biết hai cách chính phòng tránh HIV: (i) Chỉ quan hệ tình dục với một người chung thủy và không bị lây nhiễm HIV và (ii) Sử dụng bao cao su mỗi lần quan hệ tình dục (Tổng cục Thống kê, 2015). Riêng tại TP. Hồ Chí Minh, một khảo sát đánh giá kiến thức thái độ và hành vi về HIV/AIDS của phụ nữ mang thai đã chỉ ra rằng, có trên $90 \%$ người tham gia khảo sát trả lời đúng về đường lây và cách phòng tránh HIV (Nguyễn, Nguyễn, \& Phạm, 2014).

Liên quan đến thái độ kỳ thị của người dân cộng đồng đối với người có HIV và những người có liên quan, nghiên cứu của Lưu (2010) cho thấy $61.7 \%$ người dân có thái độ kỳ thị với người có HIV trong xã hội và $47 \%$ người có HIV ghi nhận thái độ xa lánh từ cộng đồng xã hội sau khi nhiễm HIV. Người kỳ thị chính là hàng xóm, láng giềng $41.3 \%$ họ hàng và bạn bè thấp hơn lần lượt là $14 \%$ và $13.4 \%$ còn tự kỳ thị là $23.4 \%$. Thêm vào đó, nghiên cứu đánh giá chỉ số kỳ thị mô tả rằng có $4 \%$ con của người có HIV không được đến trường, do sự kỳ thị của cộng đồng xã hội (VNP+, 2012). Tuy nhiên, đối với trẻ em bị ảnh hưởng bởi HIV, có những bằng chứng cho thấy khoảng trống trong nghiên cứu về nhận thức và thái độ kỳ thị của người dân cộng đồng đối với trẻ em bị ảnh hưởng bởi HIV/AIDS (BAHBH) ở Việt Nam. Bài viết này hướng tới chính những vấn đề đó với mục tiêu phân tích nhận thức về HIV/AIDS và thái độ kỳ thị của người dân cộng đồng đối với trẻ $\mathrm{BAHBH}$ ở TP. Hồ Chí Minh. Những dữ liệu trong bài viết này được rút ra từ đề tài nghiên cứu của Võ (2014) với tiêu đề "Kỳ thị đối với trẻ em bị ảnh hướng bởi HIVAIDS: Nghiên cưu tại Quận 8 và Quận Bình Thạnh, Thành phố Hồ Chí Minh". 


\section{KHÁI NIỆM, CÁC QUAN ĐIỂM VÀ PHƯƠNG PHÁP NGHIÊN CÚU CỦA SỰ KỲ TH!}

\subsection{Khái niệm kỳ thị (Stigma)}

Kỳ thị như là "một thuộc tính hết sức cá nhân và dẫn tới việc loại bỏ một người hoặc một nhóm người ra khỏi cộng đồng" và những người bình thường, coi họ là một người hoặc một nhóm người "vô dụng" và "phế phẩm". Kỳ thị như là một quá trình gồm ba bước: (i) Phân loại người "phế phẩm" ra khỏi những người "bình thường" bằng cách phân biệt và gán nhãn; (ii) Liên hệ những sự khác biệt đó với những thuộc tính xấu; (iii) Tách "chúng ta" ra khỏi "chúng nó". Kỳ thị liên quan đến HIV/AIDS đã thể hiện đầy đủ quá trình của cả ba bước này, qua việc tách và gán nhãn người có HIV và những người liên quan, gắn cho những người này là những người có hành vi "vô đạo đức" thuộc nhóm "tệ nạn xã hội" và tách họ ra như những thành phần thấp kém trong xã hội (Tổ chức Lao động Quốc tế tại Việt Nam, 2004, tr. 10). UNAIDS (2015) định nghĩa kỳ thị liên quan tới HIV/AIDS là một quá trình làm giảm giá trị (devaluation) của một cá nhân trong con mắt ngườ khác. Kỳ thị này nói đến thái độ, cảm nhận và niềm tin tiêu cực hướng đến người có HIV hoặc là liên quan với HIV.

Trẻ bị ảnh hưởng bởi HIV/AIDS được quy định theo Quyết định 570/QĐ-TTg ${ }^{1}$, nhưng trong bài viết này trẻ bị ảnh hưởng bởi HIV là trẻ nhiếm HIV và trẻ bị ảnh hưởng bởi HIV trực tiếp bao gồm: Trẻ mồ côi cha hoạc me hay cả cha và me đã chết bởi HIV/AIDS; Trẻ có cha hoặc me hoặc cả cha và mẹ, người chăm sóc trục tiếp nhiếm HIV/AIDS.

\subsection{Cơ sở lý luận}

Lý thuyết kỳ thị: Dựa theo sự công nhận của UNAIDS (2015), trong nghiên cứu này, sự kỳ thị được hiểu là một quá trình hạ thấp giá trị và làm mất đi cơ hội sống của những người có HIV hoặc những người bị nghi ngờ nhiễm HIV/AIDS và những người thân của họ bao gồm trẻ BAHBH. Rõ ràng, về mặt xã hội, kỳ thị đã cách ly những người bị kỳ thị ra khỏi xã hội hoặc cản trở họ tiếp cận các dịch vụ hỗ trợ xã hội mà đáng lý họ phải được hưởng đời sống xã hội một cách đầy đủ. Sự "kỳ thị" đề cập đến thái độ, cảm nhận và niềm tin tiêu cực hướng đến người có HIV hoặc là những người liên quan với HIV. Việc kỳ thị này đã tước đi những quyền cơ bản mà trẻ BAHBH đáng được hưởng như việc tiếp cận giáo dục, chăm sóc y tế, và vui chơi giải trí.

Lý thuyết gán nhãn (Labeling, một số tài liệu dịch dán nhãn). Howard (1963) khẳng định rằng sự lệch lạc chỉ có thể định nghĩa như "hành vi mà con người được gọi như thế" vì sự lệch lạc có tính tương đối và phụ thuộc vào tình huống tương tác xã hội cụ

\footnotetext{
${ }^{1}$ Theo quyết định 570/QĐ-TTg, ngày 22/4/2014 về Kế hoạch hành động quốc gia vì trẻ bị ảnh huởng bởi HIV/AIDS cho giai đoạn 2014-2020. Xác định đối tượng trẻ em bị ảnh hưởng bởi HIV/AIDS bao gồm: Trẻ nhiễm HIV và trẻ bị ảnh hưởng trực tiếp bởi HIV: Trẻ mồ côi do bố và mẹ hoặc bố hoặc mẹ chết vì lý do liên quan đến HIV/AIDS; Trẻ sống với bố, mẹ hoặc người nuôi dưỡng nhiễm HIV; Trẻ có nguy cơ cao nhiễm HIV: Trẻ em sử dụng ma túy, trẻ em con của người mua dâm, bán dâm, sử dụng ma túy, trẻ sống trong các cơ sở trợ giúp xã hội. Tuy nhiên trong bài viết này chỉ giới hạn trẻ bị ảnh hưởng bởi HIV là trẻ nhiễm HIV và trẻ bị ảnh hưởng bởi HIV trực tiếp.
} 
thể. Ông nhấn mạnh đến phản ứng của người khác cũng như những hệ quả của phản ứng đó là tạo ra sự lệch lạc. Khi một người đã bị gán nhãn lệch lạc, người đó sẽ trở nên bị tách rời khỏi xã hội, tìm đến với những người cùng cảnh ngộ và đến một mức độ nào đó, sẽ phản ứng theo đúng những gì mà xã hội gán cho (Howard, 1963). Lý thuyết gán nhãn được áp dụng trong nghiên cứu để mô tả sự định kiến, kỳ thị đối với trẻ BAHBH. Nó giúp tác giả mô tả được những biểu hiện của sự kỳ thị từ cộng đồng do dán nhãn. Chẳng hạn những người chăm sóc trực tiếp cho trẻ thường bị gán cho cái nhãn là những người thuộc diện "tệ nạn xã hội" hoặc là người nghiện ma túy, mại dâm hay ăn chơi lêu lổng mới bị mắc HIV và trẻ BAHBH bị xem là con "của những người tệ nạn xã hội".

\subsection{Phương pháp nghiên cứu}

Bài viết này sử dụng phương pháp nghiên cứu định lượng với bảng hỏi bán cấu trúc. Tổng số 200 người dân cộng đồng tham gia là những người đại diện trong hộ gia đình (không nhất thiết là chủ hộ), nhưng phải có con hoặc cháu trong độ tuổi từ nhà trẻ đến dưới 18 tuổi đang sinh sống tại bốn phường có nhiều trẻ BAHBH của hai Quận và họ đồng ý tham gia nghiên cứu. Trong 200 người dân cộng đồng có $61.5 \%$ là nữ giới, tuổi nhỏ nhất là 20 tuổi và lớn nhất là 86 tuổi. Độ tuổi trung bình tham gia nghiên cứu là 4059 tuổi chiếm $51 \%$; Tuổi trung vị của người dân là 46; Trình độ học vấn đa số là THCS, chiếm $55 \%$.

\section{KẾT QUẢ NGHIÊN CÚU}

\subsection{Nhận thức về HIV/AIDS của người dân cộng đồng}

Nhận thức đúng toàn diện là hiểu biết đúng về các đường lây, cách phòng tránh và phân biệt rõ ràng những quan niệm sai lầm trong lây nhiễm HIV như ăn uống chung với người có $\mathrm{HIV}$, ngủ chung, tắm chung hồ bơi với người có HIV thì không thể nào bị lây nhiễm HIV, cũng như những thông tin liên quan đến điều trị ART (Anti Retrovirus Therapy - Liệu pháp thuốc kháng vi rút HIV). Kết quả nghiên cứu chỉ ra rằng, $62 \%$ người dân cộng đồng có nhận thức đúng toàn diện đầy đủ về HIV/AIDS. Tuy nhiên, vẫn còn $38 \%$ người tham gia nghiên cứu chưa có kiến thức đúng và đầy đủ về HIV/AIDS, nên rất cần các chương trình truyền thông về HIV/AIDS tiếp tục được đẩy mạnh để cải thiện tỷ lệ người dân có nhận thức chưa đầy đủ này. So sánh giữa nam và nữ, thì có sự khác biệt đáng kể khi tỷ lệ nữ có kiến thức đúng toàn diện cao hơn nam giới lần lượt là $60.5 \%$ và $39.5 \%$ như được trình bày trong Bảng 1 . Tỷ lệ nữ có kiến thức đúng cao hơn nam giới cho thấy rằng các hoạt động truyền thông HIV/AIDS, trong thời gian qua, đã ưu tiên tập trung hơn vào phụ nữ. Bởi ngay từ đầu dịch HIV/AIDS, không ít các nghiên cứu chỉ ra rằng phụ nữ có nguy cơ lây nhiễm HIV cao hơn và chịu tác động HIV nặng nề hơn nam giới nhưng việc tiếp cận thông tin HIV/AIDS lại còn hạn chế. Vì vậy, một trong những chỉ tiêu then chốt của các Mục tiêu thiên niên kỷ và báo cáo tiến trình phòng chống HIV/AIDS toàn cầu (Global AIDS Response Progress Reporting - GARPR; Trước đây là báo cáo của United Nations General Assembly Special session on HIV and AIDS UNGASS) luôn có phần trăm phụ nữ, trẻ em và thanh niên có hiểu biết toàn diện và đúng về sự lây truyền, cách phòng tránh HIV. Trong những năm qua, Việt Nam luôn thực hiện báo cáo điều tra đánh giá các mục tiêu trẻ em và phụ nữ, gọi tắt là MICS (Multiple 
Indicator Cluster Survey), được tiến hành định kỳ hai năm để thu thập thông tin có tính so sánh toàn cầu về một loạt các chỉ tiêu phản ảnh tình trạng trẻ em và phụ nữ liên quan đến dinh dưỡng, sức khỏe, tiêm chủng mở rộng ở trẻ em, giáo dục và HIV/AIDS. Rõ ràng, các báo cáo này đã góp phần tăng cường các hoạt động truyền thông nâng cao nhận thức về HIV/AIDS cho phụ nữ và trẻ em.

Khi phân tích về đường lây truyền HIV và cách phòng tránh, kết quả cho thấy, $71 \%$ người dân cộng đồng có kiến thức đúng về các đường lây và $64 \%$ người tham gia nghiên cứu đã trả lời chính xác về cách phòng tránh HIV. So sánh giữa nam và nữ thì nữ giới xác định đúng các đường lây và cách phòng tránh HIV cao hơn nam giới theo thứ tự lần lượt $65.5 \%$ so với $34.5 \%$ và $60.2 \%$ so với $39.8 \%$ như được tóm tắt trong Bảng 1 .

Những quan niệm sai lầm về lây nhiễm HIV dễ gây ra thái độ kỳ thị, trong những năm qua truyền thông đại chúng từ trung ương đến địa phương, cùng các ban ngành, đoàn thể đã có nhiều hoạt động truyền thông để nâng cao nhận thức cho người dân, góp phần xóa những quan niệm sai lầm về HIV/AIDS như: Ăn uống chung với người có HIV, ngủ chung với người có HIV, tắm chung với người có HIV là không bị lây HIV. Điều này giúp cải thiện đáng kể những hiểu biết sai lầm của người dân. Tuy nhiên, kết quả nghiên cứu đã phản ảnh có tới $42 \%$ người dân vẫn còn quan niệm sai lầm về HIV/AIDS, khi có người dân cho rằng ngủ chung (không quan hệ tình dục) có thể lây nhiễm HIV, hay không ăn chung với người nhiễm HIV và không dùng chung nhà vệ sinh, hồ bơi để phòng tránh lây nhiễm HIV. So sánh giữa nam và nữ, thì nam bị nhầm lẫn cao hơn nữ. Bằng chứng là trong khi tỷ lệ nữ có kiến thức đúng là $65.5 \%$ thì tỉ lệ nam giới chỉ là $34.5 \%$.

Bảng 1. Tỷ lệ \% người hiểu đúng về HIV theo giới tính

\begin{tabular}{lcccc}
\hline \multirow{2}{*}{ Nội dung } & \multicolumn{2}{c}{$\begin{array}{c}\text { \% giới tính người có } \\
\text { hiếu đúng về HIV }\end{array}$} & $\begin{array}{c}\text { Tổng người có hiểu biết } \\
\text { đúng về HIV }\end{array}$ \\
\cline { 2 - 5 } & Nam & Nữ & $\begin{array}{c}\text { Số người } \\
\text { (N=200) }\end{array}$ & Tỷ lệ \% \\
\hline Kiến thức đúng toàn diện về HIV/AIDS & 39.5 & 60.5 & 124 & 62.0 \\
Kiến thức đúng về các đường lây HIV & 34.5 & 65.5 & 142 & 71.0 \\
Kiến thức đúng về cách phòng tránh HIV & 39.8 & 60.2 & 128 & 64.0 \\
Kiến thức đúng về các nhầm lẫn liên quan HIV & 34.5 & 65.5 & 116 & 58.0 \\
Kiến thức đúng về thông tin điều trị ART & 47.1 & 52.9 & 51 & 25.5 \\
\hline
\end{tabular}

Nguồn: Võ (2014).

Hiện nay khi quan điểm của các nhà chuyên môn trên thế giới và tại Việt Nam đều đang xem điều trị ART là dự phòng lây nhiễm HIV, nên việc người dân có kiển thức đúng về điều trị ART sẽ góp phần giảm kỳ thị, kết quả chỉ ra rằng, 149 người $(74.5 \%)$ chưa có kiến thức đúng về điều trị ART. Nghiên cứu cho thấy, nữ luôn có kiến thức đúng toàn diện về các đường lây, cách phòng tránh và những nhầm lẫn về HIV gần gấp đôi nam giới. Nhưng kiến thức đúng về thông tin điều trị ART giữa nam và nữ thì không có sự khác biệt đáng kể (47.1\% nam và $52.9 \%$ nữ), như vậy cả nam và nữ chỉ đúng khoảng $50 \%$ kiến thức về thông tin điều trị ART. Dường như thông tin về điều trị ART chưa thu 
hút sự quan tâm của người dân. Đây là vấn đề cần được chú ý để đẩy mạnh thông điệp truyền thông điều trị ART là dự phòng, góp phần giảm kỳ thị.

\subsection{Thái độ kỳ thị của người dân cộng đồng}

Thái độ là xu hướng phản ứng (tích cực hay tiêu cực; đồng tình ủng hộ hay không đồng tình, phản đối) của cá nhân đối với các đối tượng hay tình huống mà người đó gặp phải thông qua nhận thức, tình cảm và cách ứng xử của mình. Thái độ hình thành trong quá trình các cá nhân gia nhập vào các quan hệ xã hội và mang tính lịch sử (Nguyễn \& Trần, 2011).

Kết quả nghiên cứu cho thấy rằng, $80.5 \%$ người dân vẫn còn kỳ thị với trẻ em BAHBH. So sánh giữa nam và nữ, thì nữ có thái độ kỳ thị cao hơn nam giới gần gấp đôi (65.2\% so với $34.8 \%$ ), mặc dù hiểu biết đúng về HIV/AIDS của phụ nữ lại cao hơn nam giới. Điều này có phải chăng do phụ nữ thường nặng cảm tính với con cháu nhiều hơn nam giới, nên dễ lo sợ quá mức mà có thái độ kỳ thị?

Để có thể hiểu rõ hơn về thái độ kỳ thị của người dân cộng đồng, các tình huống cụ thể trong cuộc sống minh chứng thái độ có kỳ thị hay không của người dân. Khi được hỏi chung "trẻ em bị ảnh hưởng bởi HIV có nên đến trường họ chung với các trẻ em khác không?" thì 76.5\% người dân đã cho rằng có. Rõ ràng, đa số người dân đều muốn trẻ em bị ảnh hưởng bởi HIV cần được đến trường như bao trẻ em khác, và việc trẻ học chung chắc không bị ảnh hưởng gì. Tuy nhiên, khi được hỏi tiếp "giả sủ con, cháu ông bà ngồi chung ghế, hoc chung lớp với trẻ bi ảnh hưởng bởi HIV, ông bà cảm thấy nhu thế nào?", số người tham gia nghiên cứu cảm thấy bình thường chỉ còn $60.5 \%$, số người dân lo sợ đã chiếm 39.5\%. Mức độ lo sợ của phụ nữ (69.6\%) cao hơn gấp đôi so với nam giới $(30.4 \%)$. Mặc dù, đa số người người dân đều biết rằng việc học chung, ngồi chung ghế không thể nào bị lây nhiễm HIV, thế nhưng vẫn còn khá nhiều người $(39.5 \%)$ lại lo sợ quá mức trẻ học chung, ngồi chung với nhau sẽ có nguy cơ bị lây nhiễm HIV? Chính sự lo sợ quá mức không cần thiết này của người dân, sẽ dễ dàng tạo ra thái độ và hành vi kỳ thị đối với trẻ em bị ảnh hưởng bởi HIV. Tiếp tục với câu hỏi, "giả sủ ông bà biết trong xóm/cộng đồng có trẻ nhiễm HIV/trẻ bị ảnh hưởng bởi HIV hay đến chơi với con, cháu ông bà, vâyy ông bà có để cho con, cháu minh chơi với chúng hay không?" thì chỉ có $65 \%$ người tham gia nghiên cứu đồng ý cho chơi chung, còn $35 \%$ là không đồng ý. Tuy nhiên tỷ lệ phụ nữ phản đối trẻ chơi chung gần gấp ba lần nam giới.

Như vậy, có thể thấy rằng, khi chúng ta đưa ra các quan điểm, tình huống chung chung để đánh giá về thái độ kỳ thị, thì người dân cộng đồng bày tỏ thái độ ít kỳ thị, tuy nhiên, khi các tình huống này liên quan trực tiếp đến con, cháu của họ thì những người tham gia nghiên cứu thể hiện ngay sự dè dặt, thái độ kỳ thị càng rõ ràng hơn và phụ nữ thể hiện sự dè dặt, kỳ thị nhiều hơn nam giới. Tất cả những điều này gợi nhắc rằng, sự hiểu biết về HIV có thể khiến người ta ít kỳ thị hơn. Nhưng thái độ kỳ thị không hẳn chỉ bị chi phối bởi kiến thức mà còn bị ảnh hưởng bởi cảm xúc, bởi định kiến và bởi thực hành trong thực tế. Từ đó có thể suy diễn rằng để người dân không có thái độ kỳ thị, việc phổ biến kiến thức không thôi vẫn chưa đủ, mà còn cần có những biện pháp giúp người dân thay đổi thái độ đối với người BAHBH. 
Thái độ này ngày càng rõ ràng hơn khi được tiếp tục với câu hỏi "nếu biết một nguoơi bán quán ăn trong hẻm là nguời có HIV, ông bà sẽ có ăn hàng của nguời đó không?" kết quả phản ảnh rằng chỉ có $34 \%$ người dân đồng ý tiếp tục ăn hàng của người có HIV. Như vậy, có tới $66 \%$ người dân không dám ăn hay có thái độ kỳ thị với quán ăn của người có HIV. Có sự khác biệt đáng kể, khi tỷ lệ phụ nữ (64.4\%) cao gần gấp đôi nam giới với $35.6 \%$ còn lo lắng không dám ăn ở quán ăn của người có HIV.

Sự định kiến, gán nhãn người có HIV hoặc những người liên quan là thành phần "tệ nạn xã hội” như những nhân tố then chốt tạo ra sự kỳ thị trong cộng đồng xã hội. Kết quả nghiên cứu đã phản ảnh rằng, có $72.5 \%$ người dân còn định kiến, trong đó nữ còn định kiến cao hơn nam theo thứ tự $64.7 \%$ và $35.8 \%$.

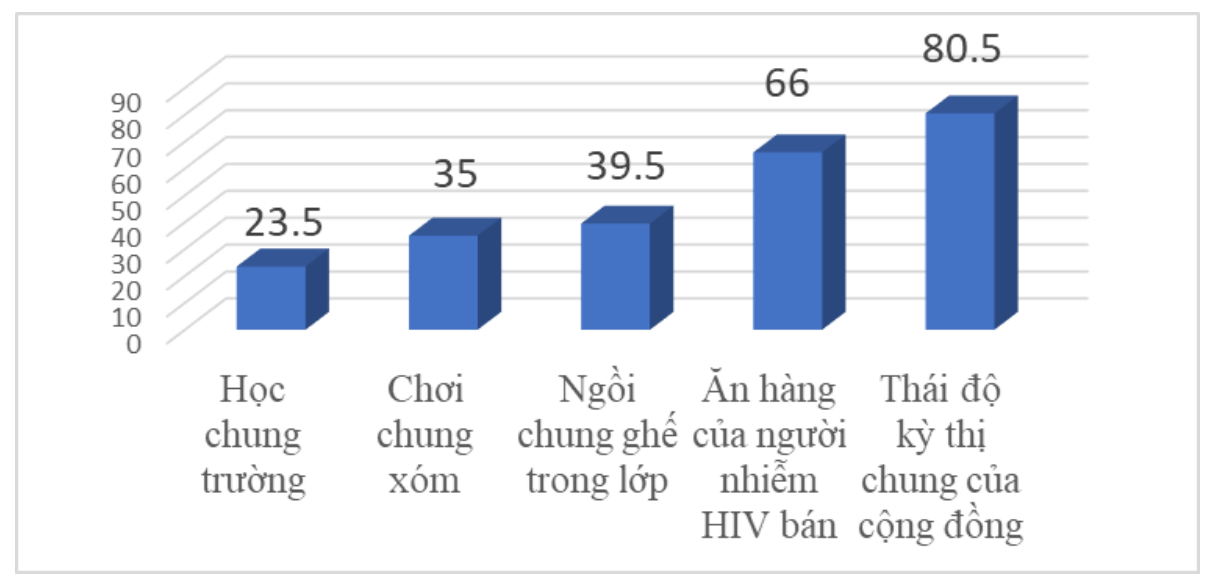

\section{Hình 1. Thái độ kỳ thị của người dân cộng đồng đối với trẻ em BAHBH (\%)}

Nguồn: Võ (2014).

\subsection{Tương quan giữa thái độ kỳ thị với các nhân tố tác động đến sự kỳ thị}

Nhằm tìm các nhân tố ảnh hưởng đến sự kỳ thị của người dân cộng đồng đối với trẻ em $\mathrm{BAHBH}$, phân tích hồi quy Logistic được sử dụng. Bảng 2 trình bày mô hình "không cho trẻ em BAHBH học chung với trẻ em khác" làm biến phụ thuộc. Các phân nhóm đặc trưng bao gồm các biến độc lập như giới tính, nhóm tuổi, học vấn, nghề nghiệp và nhận thức đúng toàn diện về HIV/AIDS. Định kiến và nhầm lẫn cũng được phân tích thử nghiệm nhưng không có tác động đáng kể có ý nghĩa thống kê, nên không đưa vào bảng. Kết quả phân tích hồi quy Logistic cho thấy có sự chênh lệnh theo giới tính giữa nam và nữ trong xác suất để cho trẻ em BAHBH học chung với trẻ khác. Hành vi cho trẻ em BAHBH học chung có xu hướng tăng từ nữ đến nam. Hay nói cách khác, nam giới có xu hướng đồng ý cho trẻ em BAHBH học chung với trẻ khác cao hơn gần gấp đôi nữ giới và sự chênh lệch này có ý nghĩa thống kê $(\operatorname{Exp}(B)=0.442 ; 95 \%$; $\mathrm{p}<0.05)$. Việc này một lần nữa xác nhận thêm cho kết quả phân tích về thái độ kỳ thị của người dân theo giới tính ở Bảng 1 . Liệu có phải nữ giới thường lo sợ quá mức về nguy cơ lây nhiễm HIV ở trẻ em nên dễ có thái độ dè dặt, kỳ thị hơn nam giới chăng? Mặc dù kiến thức đúng toàn diện về HIV/AIDS của nữ cao hơn nam giới như minh chứng trong phần nhận thức của người dân cộng đồng ở trên. Không có sự chênh lệch đáng kể giữa các nhóm tuổi của người dân cộng đồng trong việc không cho trẻ em BAHBH học chung. 
Kết quả hồi quy một lần nữa khẳng định khi các biến số khác là như nhau có trong mô hình, hệ số chênh lệch giữa xác suất không cho trẻ em BAHBH học chung với trẻ khác của người có trình độ học vấn tiểu học có xu hướng kỳ thị cao gần gấp 4 lần so với người có trình độ học vấn từ THPT trở lên, sự chênh lệch này có ý nghĩa thống kê (Exp $(\mathrm{B})=3.909 ; 95 \% ; \mathrm{p}<0.05)$. Người có trình độ học vấn THCS có xu hướng kỳ thị hơn gần gấp ba (2.8 lần) khi so với nhóm tham chiếu là trình độ THPT trở lên, nhưng không có ý nghĩa thống kê. Hay nói cách khác, người có trình độ học vấn càng thấp thì thường có xu hướng kỳ thị càng cao khi so với người có trình độ học vấn cao.

Nghề nghiệp của người dân cộng đồng lại có ảnh hưởng đến khả năng cho trẻ em BAHBH học chung. Hệ số hồi quy cho thấy, khi các biến số khác là như nhau, người làm nhân viên văn phòng có xu hướng không đồng ý cho trẻ em BAHBH học chung với các trẻ khác cao hơn 3.8 lần khi so với những người nội trợ, không việc làm và sự chênh lệch này là có ý nghĩa thống kê $(\operatorname{Exp}(\mathrm{B})=3.837 ; 95 \% ; \mathrm{p}<0.05)$. Điều này, dường như là do những nhân viên văn phòng thường không có thời gian quan tâm cập nhật thông tin mới về HIV, hay do họ luôn lo sợ quá mức về nguy cơ lây nhiễm HIV khi cho trẻ học chung với nhau, thành thử nhân viên văn phòng có xu hướng kỳ thị hơn các nhóm khác.

\section{Bảng 2. Mô hình hồi quy Logistic về xác suất không cho trẻ BAHBH học chung}

\begin{tabular}{lll}
\hline \multirow{2}{*}{ Đặc trưng } & & Mô hình (exp B) \\
\cline { 3 - 3 } Giới tính & Nam & Không cho trẻ BAHBH học chung \\
\hline \multirow{2}{*}{ Nhóm tuổi } & Nữ & $0.442^{*}$ \\
& Dưới 40 & 1 \\
& $40-54$ & 1.004 \\
Học vấn & 55 trở lên & 0.953 \\
& Tiểu học & 1 \\
Nghề nghiệp & THCS & $3.909^{*}$ \\
& THPT, trở lên & 2.815 \\
Nhận thức về HIV/AIDS & Viên chức, văn phòng & 1 \\
Hằng số & Buôn bán nhỏ, LĐ PT & $3.837^{*}$ \\
\hline & Nội trợ, không làm việc & 1 \\
\hline & Nhận thức chưa đầy đủ & $4.299^{* *}$ \\
\hline & Nhận thức đúng, toàn diện & 1 \\
\hline
\end{tabular}

Ghi chú: * là mức ý nghĩa nhỏ hơn 0.05 ; ** là mức ý nghĩa nhỏ hơn 0.01 ;

Hosmer và Lemeshow test $=0.973$. $\mathrm{N}=200$.

Nguồn: Võ (2014).

Hiểu biết về HIV có ảnh hưởng đến thái độ hành vi kỳ thị của người dân, khi kết quả hồi quy chỉ ra rằng người có hiểu biết chưa đầy đủ về HIV có xu hướng không cho 
trẻ em BAHBH học chung với trẻ khác cao hơn 4.3 lần những người dân có kiến thức đúng toàn diện về HIV, sự chênh lệch này có ý nghĩa thống kê $(\operatorname{Exp}(B)=4.299$; 95\%; $\mathrm{p}<0.01)$. Nói cách khác, người có hiểu biết chưa đầy đủ về HIV thường có xu hướng kỳ thị hơn những người có hiểu biết đúng toàn diện về HIV.

Nhìn chung, phân tích hồi quy Logistic cho thấy rằng bốn nhân tố cản trở trẻ em BAHBH học chung với trẻ khác là: (i) Giới tính; (ii) Học vấn; (iii) Nghề nghiệp; và (iiii) Hiểu biết chưa đầy đủ về HIV.

\section{KẾT LUẬN}

Nhìn chung, nhận thức đúng toàn diện về HIV của người dân cộng đồng còn khá khiêm tốn. Nữ giới có kiến thức đúng về HIV cao hơn nam giới. Trong đó, quan niệm sai lầm về đường lây và cách phòng tránh của người dân còn cao. Đặc biệt, người dân cộng đồng chưa biết thông tin chung về điều trị kháng vi rút ART. Khi người dân hiểu xu hướng hiện nay, điều trị ART cho người nhiễm HIV là dự phòng lây nhiễm HIV, thì sẽ làm cho họ bớt lo sợ và giảm sự kỳ thị cộng đồng.

Nghiên cứu cho thấy rằng thái độ kỳ thị của người dân cộng đồng đối với trẻ em bị ảnh hưởng bởi HIV/AIDS vẫn còn rất cao, đặc biệt, đối với các tình huống liên quan trực tiếp đến con, cháu của họ thì sự kỳ thị lại càng thể hiện rõ hơn. Định kiến của người dân cộng đồng đối với người có HIV còn khá nặng nề. Nhưng, nhầm lẫn về HIV và định kiến gán nhãn người có HIV với “các tệ nạn xã hội” lại không có mối tương tác với thái độ kỳ thị của người dân. Kiểm định phản ảnh rằng bốn nhân tố tác động đển thái độ kỳ thị của người dân là: (i) Giới tính; (ii) Học vấn, (iii) Nghề nghiệp, và (iiii) Hiểu biết chưa đầy đủ về HIV.

Kết quả nghiên cứu này sẽ góp phần tác động đến những nhà hoạch định chính sách, những người thực hiện chương trình, quản lý Nhà nước, truyền thông đại chúng và những người làm việc trong lãnh vực HIV/AIDS cần phải tiếp tục đẩy mạnh hoạt động truyền thông nâng cao nhận thức người dân về HIV/AIDS bao gồm thông tin mới như lợi ích điều trị sớm, điều trị ART là dự phòng lây nhiễm HIV để cho người dân không còn lo sợ quá mức và giảm thái độ kỳ thị với người có HIV và trẻ em bị ảnh hưởng bởi HIV.

\section{TÀI LIỆU THAM KHẢO}

Howard, S. (1963). Outsiders: Studies in the sociology of deviance. New York, USA: Free Press.

Lưu, B. N. (2010). Gia đình Việt Nam đối mặt với HIV/AIDS: Các thái độ kỳ thị (nghiên cứ đối chứng ở Ha Long, Việt Nam). Bài báo được trình bày tại Hội nghị Khoa học quốc gia Phòng chống HIV/AIDS lần thứ IV, Việt Nam.

Nguyễn, A. D., Nguyễn, H. T., \& Phạm, T. T. (2014). Đánh giá kiến thức thái độ hành vi về HIV/AIDS trên phu nũ mang thai tại Thành phố Hồ Chí Minh. Bài báo được trình bày tại Hội nghị Khoa học quốc gia Phòng chống HIV/AIDS lần thứ VI, 2015. 
Nguyễn, M. H., \& Trần, H. T. (2011). Thái độ của thanh thiếu niên Việt Nam về hôn nhân gia đình. Tạ chí Nghiên cúu Gia đình và Giới, (4), 3-14.

Rebeca, K. R., Vũ, H. X., \& Nguyễn, G. T. (2011). Báo cáo phân tích tình hình trẻ em năm 2010. New York, USA: UNICEF.

Tổng cục Thống kê. (2015). Điều tra đánh giá các mục tiêu phụ nũu, trẻ em năm 2014. Hà Nội, Việt Nam: Bộ Kế hoạch và Đầu tư.

Tổ chức Lao động Quốc tế tại Việt Nam. (2004). Giảm thiểu kỳ thị, phân biệt đối xủ ở noi làm việc. Hà Nội, Việt Nam: Tổ chức Lao động Quốc tế.

UNAIDS. (2010). Getting to zero (2011-2015 strategy joint united nations programme in HIV/AIDS). Genève, Switzerland: UNAIDS.

UNAIDS. (2015). UNAIDS terminology guidelines. Genève, Switzerland: UNAIDS.

Ủy ban Quốc gia Phòng chống HIV/AIDS, ma túy, mại dâm. (2012). Chiến lược quốc gia phòng chống HIV/AIDS đến năm 2020 và tầm nhìn 2030. Hà Nội, Việt Nam: Ủy ban Quốc gia Phòng chống HIV/AIDS, ma túy, mại dâm.

VNP+ (2012). Nghiên cứu về chỉ số đánh giá mức độ kỳ thị người có H tại Việt Nam. Hà Nội, Việt Nam: Mạng lưới quốc gia những người sống với HIV/AIDS của Việt Nam.

Võ, H. S. (2014). Kỳ thị đối với trẻ em bị ảnh hưởng bởi HIV/AIDS: Nghiên cứu tại Quận 8 và Quận Bình Thạnh, Thành phố Hồ Chí Minh. (Luận án Tiến sĩ), Viện Hàn lâm Khoa học Xã hội Việt Nam, Học viện Khoa học Xã hội. 